\title{
Avaliação ambiental da utilização de solo contaminado por derivados de petróleo (SCDP) em misturas asfálticas
}

\author{
Victor Mosca de Carvalho Araujo', Verônica Teixeira Franco Castelo Branco², Danielle Monteiro de Lima e \\ Rivelino Martins Cavalcante ${ }^{4}$
}

\begin{abstract}
Resumo: Com a necessidade de uma destinação final mais adequada a vários resíduos, a utilização de resíduos na pavimentação surge como uma alternativa viável. O presente estudo investiga a viabilidade técnica e ambiental da utilização de Solo Contaminado por Derivados de Petróleo (SCDP) em misturas do tipo Areia Asfáltica (AA) usinadas à quente com adição de $30 \%$ em massa de SCDP, com e sem a utilização da cal. As misturas asfálticas foram compactadas através da metodologia Superpave. Os materiais componentes das misturas asfálticas foram analisados através de ensaios convencionalmente requeridos pelas especificações do DNIT e através dos seguintes ensaios: (i) fluorescência por Raio-X, (ii) lixiviação (NBR 10.005), e (iii) solubilização (NBR - 10.006). As amostras com resíduos foram avaliadas de três formas: (i) puras,(ii) a partir de misturas asfálticas no estado solto, e (iii) a partir da água obtida após a percolação desta em Corpos de Provas (CPs) de misturas asfálticas com $30 \%$ de resíduo incorporado em massa. As misturas asfálticas foram caracterizadas mecanicamente por meio dos ensaios de módulo de resiliência, resistência à tração e vida de fadiga. A partir dos resultados encontrados nos ensaios mecânicos e ambientais, o uso do SCDP como componente de misturas do tipo AA se mostra como uma opção viável, pois, além desta mistura asfáltica ter apresentado propriedades mecânicas aceitáveis, a solução foi considerada ambientalmente aceitável e menos onerosa se comparada aquela comumente adotada pelas refinarias geradoras do resíduo.

Palavras-chave: avaliação ambiental, misturas asfálticas, solo contaminado por derivados de petróleo.
\end{abstract}

\begin{abstract}
With the need for a proper final disposal for different wastes, its use as a pavement material comes about as a potential alternative. This study investigates the feasibility of the use of soil contaminated by petroleum products (SCPP) in sand asphalt mixtures prepared with $30 \%$ of SCPP by weight. Environmental aspects of the mixtures were assessed using the following tests: (i) X-ray fluorescence, (ii) leaching (NBR - 10,005), and (iii) solubilization (NBR - 10,006). The hazardous substances encapsulation was verified by adding lime to the investigated mixtures. The residues samples were evaluated in two ways: pure and using asphalt mixtures designed with this waste material. The mixtures were also investigated with respect to its mechanical properties using tests such as resilient modulus, indirect tensile strength and fatigue life. According to the mechanical and environmental tests results, the use of SCPP in sand asphalt mixtures can be a reasonable option, since, besides the fact that these mixtures presented satisfactory mechanical properties, this SCPP destination is environmentally feasible and less expensive.
\end{abstract}

Keywords: environmental evaluation, hot asphalt mixture, soil contaminated by petroleum products.

\section{INTRODUÇÃO}

O processo de degradação do meio ambiente tem sido proporcional à evolução da sociedade. Entre as problemáticas ambientais incluem-se desmatamentos, geração e descarte de resíduos, aquecimento global, entre outras. Preocupar-se com o descarte e a possível reutilização de resíduos se torna então uma necessidade. Neste sentido, na pavimentação, autores vêm estudando o reuso de diversos materiais. Antunes et al. (2010) avaliaram o potencial de contaminação de diferentes resíduos incorporados às misturas asfálticas através dos resultados de ensaios de solubilização e de lixiviação, entre estes materiais analisados está o Solo Contaminado por Derivados Petróleo (SCDP). A mistura asfáltica contendo o material citado foi classificada, neste citado

\footnotetext{
1 Victor Mosca de Carvalho Araujo 1, Departamento de Engenharia de Transportes, UFC. (mosca.victor@hotmail.com)

2 Verônica Teixeira Franco Castelo Branco, Departamento de

Engenharia de Transporte, UFC. (veronica@det.ufc.br)

${ }^{3}$ Danielle Monteiro de Lima, Instituto de Ciências do Mar, UFC.

(danitslima@gmail.com)

${ }^{4}$ Rivelino Martins Cavalcante, Instituto de Ciências do Mar, UFC.

(rivelino@labomar.ufc.br)
}

Manuscrito recebido em 05/07/2015 e aprovado para publicação em 04/04/2015

Este artigo é parte de TRANSPORTES v. 24, n. 2, 2016. ISSN: 2237-1346 (online). DOI:10.4237/transportes.v24i2.961 estudo, como resíduo perigoso Classe I. A análise da viabilidade ambiental do uso de resíduo com potencial contaminante em estruturas de pavimentos é necessária para garantir a adequabilidade da disposição final escolhida.

Há casos em que o potencial de contaminação do resíduo, apesar de reduzido ao ser incorporado na estrutura de pavimentos, ultrapassa os Valores Máximos Permitidos (VMPs) determinados na NBR 10.004(2004a), podendo gerar graves consequências ao ambiente. Para reduzir a percolação de substâncias com potencial contaminante contidas nos líquidos lixiviados destes pavimentos é utilizada a técnica da solidificação/estabilização, também conhecida como encapsulamento. Cordeiro (2007) estudou a estabilização química e a solidificação do resíduo oleoso gerado nas atividades de exploração e de produção de petróleo para uso em camadas granulares de pavimentos. Este autor comprovou que a incorporação da cal ao solo (3 a 9\%) gerou redução da toxicidade, devido a estabilização química e a solidificação realizada pela cal.

Durante o processo de refino e de transporte do petróleo, através de oleodutos e de tanques de armazenamento, é possível que ocorra o vazamento deste material e a, consequente, contaminação do solo subjacente, gerando um resíduo de difícil utilização e de descarte oneroso. A forma encontrada para descartar esse material é a queima do mesmo em cimenteiras, onde as cinzas são incorporadas 
ao cimento. Porém, esta alternativa pode ser onerosa $(\mathrm{Ca}-$ valcante, 2010). O uso do SCDP na pavimentação surge como uma alternativa de descarte interessante do ponto de vista técnico, ambiental e econômico (Aldigueri et al., 2004; Onofre et al., 2009).

Para que o uso do SCDP no pavimento seja difundido, além da viabilidade técnica, deve-se também avaliar a viabilidade ambiental, uma vez que o SCDP é constituído por elementos e substâncias considerados contaminantes ambientais. A viabilidade ambiental deve ser avaliada com o intuito de verificar o potencial de contaminação dos compartimentos ambientais, especialmente dos recursos hídricos. O objetivo principal do presente trabalho é avaliar a viabilidade técnica e ambiental, da utilização de $30 \%$ em massa de SCDP, como componente de misturas do tipo Areia Asfáltica (AA). Os dados oriundos do estudo serão importantes na gestão de resíduos sólidos em termos de disposição final, de um passivo constituído por material perigoso ao equilíbrio ambiental.

\section{REVISÃO BIBLIOGRÁFICA}

\subsection{Solo Contaminado por Derivados de Petróleo (SCDP)}

O refino do petróleo é importante para a população mundial devido às suas várias aplicações, porém o seu alto potencial contaminante não pode ser desconsiderado. Oleodutos em más condições de manutenção podem acarretar a contaminação de grandes extensões de solo, além de oferecerem riscos com relação à contaminação do lençol freático (Onofre et al., 2009). Um dos contaminantes provenientes de fontes petrolíferas são os Hidrocarbonetos Policíclicos Aromáticos (HPAs), que fazem parte de um grupo de compostos classificados como Poluentes Orgânicos Persistentes (POPs). Esses contaminantes apresentam propriedades mutagênicas(que podem causar mutações genéticas), carcinogênicas (que pode sensibilizar o organismo para o surgimento do câncer) e teratogênicas (que podem trazer anormalidades morfológicas ou funcionais ao produto da concepção), e são caracterizados como ambientalmente estáveis, resistentes à degradação, sendo também bioacumuláveis, hidrofílicos e tóxicos (Witt, 2002).

No estado do Ceará, alguns autores já estudaram a adição de SCDP em misturas asfálticas e em camadas granulares de pavimentos. Aldigueri et al. (2004) investigaram misturas do tipo Concreto Asfáltico (CA) com emprego de SCDP em proporções em massa de 10 a $40 \%$. Esses autores comprovaram que misturas com percentuais em massa de até $30 \%$ de SCDP apresentaram valores compatíveis com aqueles encontrados na literatura para Módulo de Resiliência (MR) e Resistência à Tração (RT) para misturas asfálticas que não utilizaram resíduos em sua composição, destacando que estas misturas apresentam valores de Volume de vazios (Vv) e Relação Betume-Vazios (RBV) que não satisfaziam àqueles determinados pelo então Departamento Nacional de Estradas de Rodagem (DNER). Porém, os autores julgaram que estes parâmetros nem sempre caracterizavam uma mistura adequadamente para a pavimentação, especialmente quando estas contêm resíduos em sua composição. Onofre et al. (2009) avaliaram a viabilidade técnica de AA com diferentes teores de $\operatorname{SCDP}(10,20$ e 30\%) em sua composição e concluíram ser tecnicamente viável a utilização desse resíduo para serviços de pavimentação, desde que este seja utilizado em Rodovias de Baixo Volume de Tráfego (RBVT). Na Fazenda Belém em Icapuí - Ce, foi construído um trecho experimental de $20 \mathrm{~km}$ de extensão, com revestimento utilizando $20 \%$ de SCDP em massa como agregado na composição do CA (Aldigueri et al., 2004).

\subsection{Ferramentas para Caracterização Ambiental}

Com o uso de resíduos geralmente classificados como perigosos, ou de origem desconhecida, no projeto de misturas asfálticas, justifica-se a preocupação com a possibilidade de contaminação do ambiente através, principalmente, do carreamento de substâncias perigosas pela água da chuva. Para tanto, se faz necessário o uso de métodos que possibilitem reproduzir o contato real da chuva com o pavimento contendo resíduo em sua composição e, posteriormente, gerar amostras de líquidos percolados com o objetivo de realizar a análise química dos mesmos. Farias (2005) utilizou células de percolação para simular o contato da água da chuva com as camadas de um pavimento contendo cinza pesada (resíduo da queima do carvão mineral nas usinas termelétricas) em sua composição. Este mesmo autor, utilizou tubulações em PVC e camadas drenantes para coletar o líquido percolado no contato solo-cinza. No estudo, notou-se que o aumento do percentual de cinza pesada nas misturas não significou, necessariamente, um aumento das concentrações dos elementos monitorados.

Ubaldo et al. (2011) construíram um simulador de chuva para gerar líquido percolado em uma camada de pavimento contendo borra oleosa em sua composição. A camada de pavimento a ser analisada foi executada dentro de um tanque, sobre o qual foi construído o simulador de chuva com a utilização de três barras metálicas. Nestas barras, foi passada uma mangueira contendo bicos injetores de água espaçados. As coletas do líquido percolado foram realizadas em três pontos: no fundo do tanque através da drenagem já existente, acima e no meio da camada de solo através de tubos instalados em orifícios feitos nestes pontos. Através da análise do líquido percolado, os autores concluíram que o uso da borra oleosa juntamente com material pétreo em RBVT é viável técnica e ambientalmente, contudo, por ser um resíduo heterogêneo, essa afirmativa e válida apenas para a amostra estudada.

\subsection{Encapsulamento e Uso da Cal na Pavimentação}

A recuperação ou a reutilização de solos oriundos de áreas contaminadas tem sido uma preocupação constante. Nesse contexto o ponto que mais exige atenção é a busca por técnicas que possam ser utilizadas com o intuito de reter e de isolar substâncias contaminantes. Entre estas técnicas está o encapsulamento (Rojas et al., 2009). Os agentes encapsulantes mais utilizados são o cimento e a cal. Ambos agem da mesma forma, alcalinizando o meio, elevando o pH e, consequentemente, diminuindo a solubilidade do contaminante na presença do líquido lixiviante, já que a solubilidade deste depende do pH (Heineck et al., 2007). Este parâmetro influencia os ecossistemas aquáticos naturais devido aos seus efeitos na fisiologia de diversas espécies. Para que se conserve a vida aquática, o $\mathrm{pH}$ ideal deve variar entre 6 e 9 (Esteves, 1998). Além de ter um baixo custo, o encapsulamento gera uma queda no potencial de contaminação do resíduo. Pelos motivos citados, esta técnica vem se tornando uma importante alternativa para a disposição de resíduos 


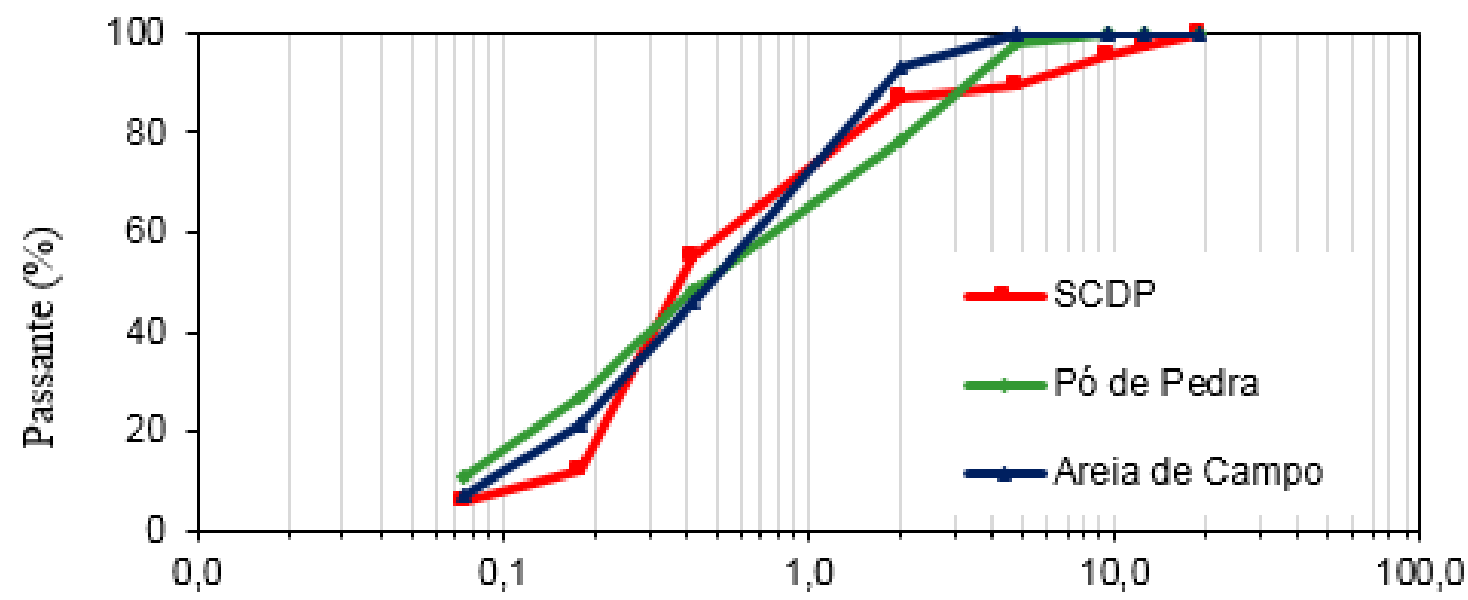

Figura 1. Abertura das peneiras ( $\mathrm{mm}$ ). Granulometria dos agregados minerais e do resíduo (SCDP) utilizados no estudo

perigosos em aterros e para o controle de áreas contaminadas (Oliveira et al., 2003).

A cal já é usada há bastante tempo na pavimentação como estabilizante de solos em camadas granulares e como fíler em misturas asfálticas como melhorador da adesividade. Moura (2001) estudou o efeito de aditivos químicos e da cal como melhoradores de adesividade em misturas asfálticas densas. Este autor concluiu que, a adição de $2 \%$ de cal melhora a adesividade na interface ligante asfáltico/agregado, não apresentando perda de RT se comparada às misturas sem e com menor quantidade de cal. Francisco e França (2007) apresentaram diversos métodos de tratamento de resíduos de petróleo, entre eles, a cal aparece como possível encapsulante (solubilização/estabilização) de substâncias perigosas.

\section{MATERIAIS E MÉTODOS}

\subsection{Materiais}

Nesta pesquisa, utilizou-se o Cimento Asfáltico de Petróleo (CAP 50/70) com Performance Grade (PG) 70-28, proveniente da Petrobras/Lubnor. Como demais materiais constituintes das misturas asfálticas, optou-se por utilizar areia de campo e pó de pedra ambos provenientes da Pedreira MFT Ltda. As densidades reais desses materiais foram 2,634 e 2,643, respectivamente. A Figura 1 apresent: as curvas granulométricas dos materiais utilizados, além di granulometria do SCDP. Além dos materiais já citados, foi utilizada ainda a cal hidratada tipo $\mathrm{CH}$-I na composição das misturas asfálticas avaliadas nesse estudo.

\subsection{Coleta e Caracterização do SCDP}

O SCDP utilizado é proveniente de derramamentos e de limpezas de dutos de petróleo de uma refinaria do Ceará. O resíduo foi recebido em barris com capacidade para aproximadamente 160 litros cada (Figura 2). Para caracterizar o SCDP foi necessário destorroar o material de modo a amenizar as dificuldades relativas a sua utilização devido à heterogeneidade do mesmo, sendo possível eliminar matérias orgânicas presentes e demais resíduos alheios ao SCDP, como pedras e restos de madeira. Em seguida, foram separadas três porções do SCDP através de quarteamento (DNER-PRO 199/96). Cada amostra separada foi caracterizada de forma a obter-se o teor de contaminação e a granulometria do material. A contaminação média das amostras por derivados de petróleo foi de $10,47 \%$. A extração do contaminante foi realizada através da utilização do Rotarex (DNER-ME 053/94).

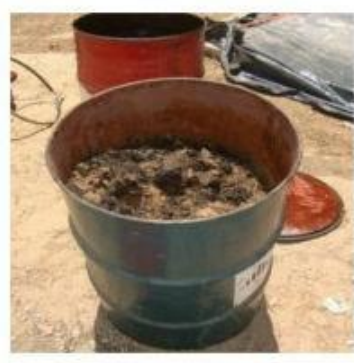

(a) Recebimento do SCDP

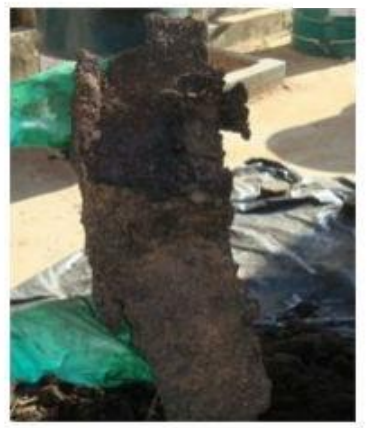

(b) Matéria orgânica encontrada no SCDP

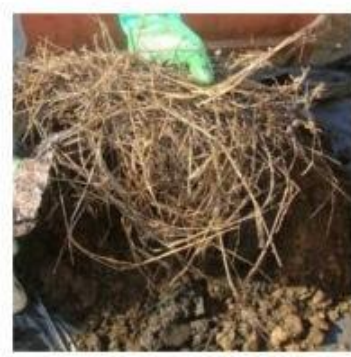

(b) Matéria orgânica encontrada no SCDP

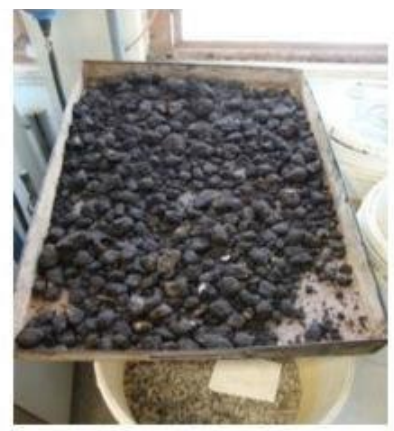

(c) SCDP antes do destorroamento
Figura 2. SCDP utilizado na presente pesquisa

\subsection{Procedimento de Dosagem das Misturas Asfálticas}

Para a realização das dosagens das misturas asfálticas foi estimado um teor provável de projeto através da fixação do Vv das mesmas. Foi adotada a faixa granulométrica $\mathrm{C}$ do DNIT para misturas do tipo AA, adotando-se o método de compactação por amassamento. Foram confeccionadas misturas do tipo AA, como mostra a Tabela 1. Como a AA tem uma ampla aceitabilidade com relação a faixa de $\mathrm{Vv}$, optou-se por realizar o procedimento de dosagem estipulando-se um percentual de Vv igual a $7 \%( \pm 0,4 \%)$, visto que um $\mathrm{Vv}$ menor tornaria o teor de CAP muito alto. A Figura 3 mostra as curvas granulométricas das misturas asfálticas avaliadas neste estudo. 
Tabela 1. Parâmetros de dosagem

\begin{tabular}{lccccccc}
\multicolumn{1}{c}{ Tabela 1. Parâmetros de dosagem } \\
Mistura & Composição & $\begin{array}{c}\text { Teor de } \\
\text { Projeto de CAP } \\
(\boldsymbol{\%})\end{array}$ & $\begin{array}{c}\text { Teor CAP } \\
\text { Virgem } \\
(\boldsymbol{\%})\end{array}$ & Vv (\%) & RBV (\%) & $\begin{array}{c}\text { VCB } \\
(\%)\end{array}$ & Gmm \\
\hline I & $\begin{array}{c}\text { 100\% de agregado } \\
\text { natural }\end{array}$ & 8,0 & 8,0 & 7,0 & 71,0 & 17,1 & 2,358 \\
II & $\begin{array}{c}\text { 70\% de agregado natural e } \\
\text { 30\% SCDP }\end{array}$ & 8,2 & 5,0 & 7,2 & 70,9 & 17,4 & 2,345 \\
III & $\begin{array}{c}\text { 68\% de agregado natural, } \\
\text { 30\% de SCDP e 2\% de cal }\end{array}$ & 7,8 & 4,5 & 7,3 & 70,0 & 16,5 & 2,343 \\
\hline
\end{tabular}

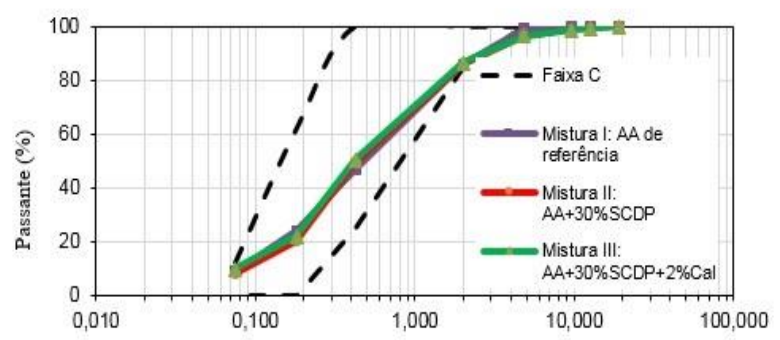

Figura 3. Composição granulométrica das misturas do tipo $A A$ avaliadas

Com os resultados da extração do contaminante do SCDP, foi possível calcular o fator de redução que desconta a quantidade de contaminante que compõe o SCDP, obtendo assim a real massa de SCDP a ser adicionada a mistura. O contaminante existente no SCDP é incorporado à mistura asfáltica simplificadamente em substituição ao CAP. Na Tabela 1 são apresentados os parâmetros encontrados para as três misturas asfálticas avaliadas nesta pesquisa, onde foi possível constatar que os parâmetros volumétricos das misturas estão coerentes com as especificações do DNIT ES 032/2005. Os Vvs das misturas analisadas foram calculados de acordo com a ASTM D2041, utilizando o parâmetro Maximum Theoritical Specific Gravity of Mixture $(\mathrm{Gmm})$. A Tabela 1 apresenta os teores de projeto de ligante asfáltico puro mais o contaminante presente no resíduo.

\subsection{Viabilidade Ambiental}

A viabilidade ambiental foi estimada em termos dos impactos promovidos pela adição de SCDP a mistura asfáltica. Experimentos de dissolução e de lixiviação foram executados a fim de verificar se os constituintes das misturas eram disponibilizados para o meio líquido, simulando, assim, processos de lixiviação semelhantes aos que podem ocorrer no ambiente em caso de uso desse material em serviços de pavimentação.

\subsubsection{Parâmetros Investigados}

Em virtude da ausência de uma legislação específica para esse material, foram utilizadas como referências as normas: NBR 10.005(2004b) e 10.006(2004c), assim como a Portaria 518/2004 do Ministério da Saúde e a Resolução CONAMA 357/2005 do Ministério do Meio Ambiente. Os parâmetros analisados foram: níveis de sulfato $\left(\mathrm{SO}_{2}\right)$, condutividade, $\mathrm{pH}$, cor aparente e quantidade de óleos e graxas. Quanto aos parâmetros orgânicos, foram avaliados aqueles contidos na norma NBR 10.006(2004c). Apesar dos HPAs não fazerem parte dessa norma, como os mesmo são muito comuns em resíduos de combustíveis fósseis (Fernandes et al., 2009), foram determinados: benzo(a)pireno; benzo(b)fluoranteno; benzo(k)fluoranteno; dibenzo(a,h)antraceno e criseno (CONAMA 357/2005).

\subsubsection{Experimentos de Dissolução e de Lixiviação}

A viabilidade ambiental foi estimada em termos experimentais a partir de ensaios de dissolução e de lixiviação. Para o ensaio de dissolução, foi utilizado $1,1 \mathrm{~kg}$ das Misturas I, II e III (Tabela 1) não compactadas em 5 litros de água supra pura (Sistema Milli-Q, Millipore) em um sistema BET (Batch Equilibration Technique) por duas horas, seguindo a norma NBR 10.006(2004c). Após esse período, a fração líquida, contendo o material dissolvido, foi separada e acondicionada em garrafas âmbares até o momento das análises dosparâmetros investigados. Além das misturas, a água Mili-Q também foi analisada para efeito de comparação, sendo esta chamada de Branconeste presente trabalho.

Apesar da praticidade dos testes já mencionados, a avaliação através dos ensaios de lixiviação e de

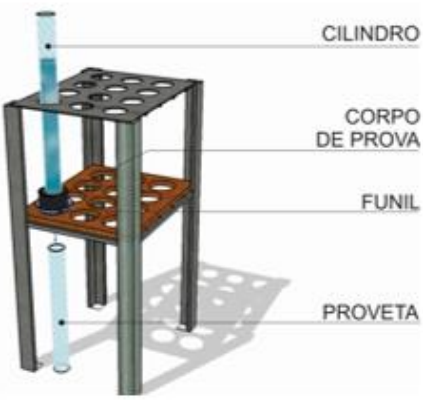

(a) Esquema das células de percolação

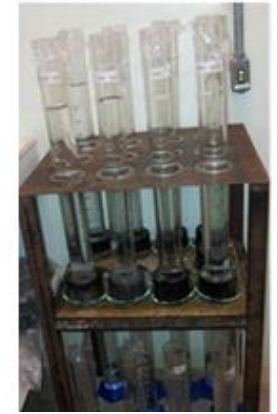

(b) Células de percolação

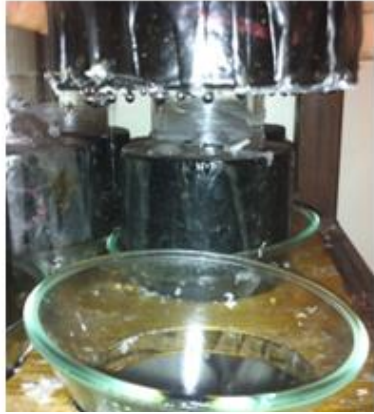

(c) Passagem de solução

Figura 4. Células de percolação utilizadas no estudo 
solubilização não retrata com fidelidade o que ocorre em campo, já que nestes ensaios as misturas não são compactadas e passam por processos condicionantes os quais são mais severos se comparados aqueles que ocorrem com o pavimento. No intuito de buscar um meio de se aproximar mais da realidade em campo, foram construídas células de percolação nas quais foi realizada a percolação de água Mili-Q pelo interior dos Corpos de Prova (CPs) com $\mathrm{Vv}$ de $10 \%( \pm 0,4)$ com o objetivo de representar as características volumétricas do revestimento logo após a compactação.

Para construir as células de percolação foram utilizados nove conjuntos. Em cada conjunto havia um cilindro, uma proveta e um funil de vidro. Os cilindros (raio de $3 \mathrm{~cm}$ ) foram fixados sobre os CPs na posição axial com a utilização de parafina, esta por sua vez recobriu toda a lateral do CP deixando apenas a parte inferior descoberta forçando a solução a passar por toda a camada da mistura asfáltica. Após a fixação do cilindro e o recobrimento dos CPs com a parafina, o CP foi colocado sobre o funil (raio de $6 \mathrm{~cm}$ ), que por sua vez foicolocado sobre a mesa utilizada como apoio através de furos (raio de $5 \mathrm{~cm}$ ). Para estabilizar as torres, foi construído um suporte com 12 furos por onde os cilindros passaram. Para coletar o líquido percolado foi colocada uma proveta logo abaixo do funil. Neste ensaio foi analisada somente a Mistura III (contendo SCDP e cal) por ter sido a mistura contendo SCDP que apresentou as melhores características mecânicas, além de ter apresentado uma diminuição na liberação de alumínio (Al), de ferro $(\mathrm{Fe})$, de manganês $(\mathrm{Mn})$ e de sulfato nos ensaios de lixiviação e de solubilização. A Figura 4 mostra a montagem das células de percolação e a passagem da solução percolada.

\subsubsection{Métodos Utilizados}

A caracterização elementar do SCDP foi realizada através da técnica de fluorescência de Raio-X. Para a determinação da presença de sulfato na fração líquida foi utilizado a metodologia de turbidimetria, método de medição da redução de transmissão de luz em um meio devido a presença de partículas (Bezerra et al., 2012). A condutividade, o pH, a cor aparente e a presença de óleos e graxas foram determinados utilizando procedimentos do Standard Methods(1998). A extração e a quantificação dos compostos orgânicos foram realizadas através da extração líquido-líquido seguida da quantificação por cromatografia gasosa uitlizando um GC-MS da marca Agilent (Cavalcante et al., 2007).O controle de qualidade foi realizado através de amostras em Branco, de curvas de calibração e da quantificação em triplicata, garantindo assim a qualidade dos dados.

\section{DISCUSSÃO DOS RESULTADOS}

\subsection{Caracterização do SCDP}

Com o objetivo de obter a caracterização química do SCDP e a proporção entre seus elementos, o ensaio de fluorescência de Raio-X foi realizado no Departamento de Física da UFC. Foi realizado o mapeamento químico e a varredura da amostra através da análise química semiqualitativa (identificação dos elementos presentes) e semiquantitativa (proporção de cada elemento). Essa técnica identifica os elementos químicos compreendidos entre o flúor e o urânio. Neste ensaio pode ser usada uma fonte de radiação gama ou radiação $X$, onde esta deve ser de elevada energia para provocar excitações nos átomos da substância que se deseja analisar. A fonte emite fótons que são absorvidos pelos elétrons da amostra através do efeito fotoelétrico fazendo-os deslocar para uma camada eletrônica mais interna. Assim, ao retornar a sua camada de origem, o elétron libera uma energia em forma de fóton correspondente a transição eletrônica. $\mathrm{O}$ espectro de energia correspondente a essa transição é único para cada elemento, o que possibilita a sua identificação (Silva, 2002). Para a realização do ensaio é necessário $1 \mathrm{~g}$ da amostra de resíduo passante na peneira $\mathrm{N}^{\mathrm{o}} 200(75 \mu \mathrm{m})$.

O ensaio foi realizado com duas amostras de SCDP, antes e depois do processo de aquecimento com as mesmas temperaturas utilizadas nos processos de mistura e de compactação das misturas asfálticas, com o objetivo de verificar as possíveis modificações sofridas pelo resíduo durante este processo. A Tabela 4 mostra os resultados do ensaio de fluorescência de Raio-X. Observa-se que alguns elementos, tais como silício $(\mathrm{Si})$, ferro $(\mathrm{Fe})$ e cloro $(\mathrm{Cl})$ tiveram seus percentuais elevados e outros elementos, como fósforo $(\mathrm{P})$, zircônio $(\mathrm{Zr})$ e manganês $(\mathrm{Mn})$ tiveram seus percentuais reduzidos ou anulados. Estes resultados se devem ao processo de aquecimento e às possíveis reações que ocorrem no próprio material quando este entra em contato com temperaturas elevadas.

Com o objetivo de caracterizar a periculosidade do resíduo e das misturas asfálticas contendo este resíduo, utilizou-se os procedimentos: NBR 10.005(2004b) (Lixiviação de Resíduos) que tem a função de caracterizar o material sólido como classe I - perigoso ou classe II - não perigoso, a depender dos elementos presentes no mesmo; e NBR 10.006(2004c) (Solubilização de Resíduos) que tem a função de caracterizar o material como classe IIA - não inerte e classe IIB - inerte. Para o ensaio de solubilização, tem-se $0,01 \mathrm{mg} / \mathrm{l}$ como VMP de fenóis totais. No SCDP foram encontrados $0,03 \mathrm{mg} / \mathrm{l}$ de fenóis totais. Foi encontrado, nos Parâmetros Complementares (PC) para a classificação da massa bruta, a presença de fenóis, por esse motivo o resíduo foi definido com Classe I - Perigoso. Para o ensaio de lixiviação não foi encontrada a presença de fenóis totais para a amostra analizada. A Tabela 5 apresenta os resultados dos ensaios de lixiviação e de solubilização realizados no SCDP.

\subsection{Viabilidade Técnica das Misturas Asfálticas}

Os ensaios de MR (DNIT 135/2010) e RT (DNIT 136/2010) foram realizados. Os CPs (três por mistura) foram condicionados a $25^{\circ} \mathrm{C}$. A Tabela 6 mostra os resultado destes ensaios.

Tabela 4. Resultados de fluorescência de Raio-X para o SCDP

\begin{tabular}{lcccccccccccccccccc}
\hline \multicolumn{11}{c}{ Elementos Químicos (\%) } \\
\hline Amostra & $\mathrm{Si}$ & $\mathrm{Fe}$ & $\mathrm{Al}$ & $\mathrm{Ca}$ & $\mathrm{K}$ & $\mathrm{S}$ & $\mathrm{Ti}$ & $\mathrm{P}$ & $\mathrm{Zn}$ & $\mathrm{Cl}$ & $\mathrm{Mn}$ & $\mathrm{Zr}$ \\
\hline Sem aquecimento & 63,42 & 10,79 & 9,23 & 6,07 & 4,81 & 2,38 & 1,83 & 0,5 & 0,38 & 0,24 & 0,22 & 0,15 \\
Com aquecimento & 65,86 & 11,58 & 8,04 & 5,40 & 4,71 & 2,24 & 1,47 & - & 0,23 & 0,24 & - & - \\
\hline
\end{tabular}

TRANSPORTES, v. 24, n. 2 (2016), p. 77-87 
Tabela 5. Parâmetros químicos no lixiviado e no solubilizado do SCDP utilizado no estudo

\begin{tabular}{|c|c|c|c|c|}
\hline \multirow[t]{2}{*}{ Parâmetro } & \multicolumn{2}{|c|}{ Solubilizado (mg/L) } & \multicolumn{2}{|c|}{$\begin{array}{c}\text { Lixiviado (mg/L) } \\
10.006\end{array}$} \\
\hline & Resultado & VMP & Resultado & VMP \\
\hline \multicolumn{5}{|c|}{ INORGÂAICOS } \\
\hline Alumínio (Al) & $<0,010$ & 0,200 & - & - \\
\hline Arsênio (As) & $<0,005$ & 0,010 & $<0,005$ & 1,000 \\
\hline Bário (Ba) & 0,200 & 0,700 & 0,500 & 70,000 \\
\hline Cádmio (Cd) & $<0,001$ & 0,005 & $<0,001$ & 0,500 \\
\hline Chumbo $(\mathrm{Pb})$ & $<0,001$ & 0,010 & $<0,001$ & 1,00 \\
\hline Cianeto $(\mathrm{CN})$ & $<0,010$ & 0,70 & - & - \\
\hline Cloreto $(\mathrm{Cl})$ & $<5,000$ & 250,000 & - & - \\
\hline Cobre $(\mathrm{Cu})$ & $<0,020$ & 2,000 & - & - \\
\hline Crômio total & $<0,020$ & 0,050 & $<0,020$ & 5,00 \\
\hline Fenóis totais & 0,030 & 0,010 & - & - \\
\hline Ferro (Fe) & 0,040 & 0,300 & - & - \\
\hline Fluoreto (F) & 0,120 & 1,500 & 0,160 & 150,000 \\
\hline Mangânes (Mn) & 0,10 & 0,100 & - & - \\
\hline Mercúrio $(\mathrm{Hg})$ & $<0,001$ & 0,001 & $<0,001$ & 0,100 \\
\hline Nitrato (N) & 0,030 & 10,000 & - & - \\
\hline Prata $(\mathrm{Ag})$ & 0,020 & 0,050 & $<0,020$ & 5,000 \\
\hline Selênio (Se) & $<0,005$ & 0,010 & $<0,005$ & 1,000 \\
\hline Sódio (Na) & 7,300 & 200,00 & - & - \\
\hline Sulfato (SO42-) & $<10,000$ & 250,000 & - & - \\
\hline Surfactantes & 0,020 & 0,500 & - & - \\
\hline Zinco (Zn) & 1,140 & 5,000 & - & - \\
\hline $\mathrm{pH}$ final & \multicolumn{2}{|c|}{7,790} & \multicolumn{2}{|c|}{5,030} \\
\hline \multicolumn{5}{|c|}{ ORGÂANICOS } \\
\hline Benzeno & - & - & $<2,000$ & - \\
\hline Cloreto & - & - & 8,000 & - \\
\hline Clorofórmio & - & - & $<2,000$ & - \\
\hline 1,2-dicloroetano & - & - & $<2,000$ & - \\
\hline 1,1-dicloroetano & - & - & $<2,000$ & - \\
\hline Tetracloroetano & - & - & $<2,000$ & - \\
\hline $\begin{array}{l}\text { Tetracloreto de } \\
\text { Carbono }\end{array}$ & - & - & $<2,000$ & - \\
\hline Tricloroeteno & - & - & $<2,000$ & - \\
\hline
\end{tabular}

As Misturas II e III (com utilização de SCDP) apresentaram propriedades mecânicas superiores se comparadas às encontradas para a mistura de referência (Mistura I) e superiores aos valores usualmente encontrados para AA. Ressalta-se ainda que, a presença da cal tornou a Mistura III aproximadamente $27 \%$ mais rígida se comparada a Mistura II.

Tabela 6. Resultados de MR e RT

\begin{tabular}{|c|c|c|c|}
\hline Mistura & Composição & $\begin{array}{c}\text { MR } \\
(\mathrm{MPa})\end{array}$ & $\begin{array}{c}\text { RT } \\
(\mathbf{M P a})\end{array}$ \\
\hline $\bar{I}$ & $100 \%$ de agregado natural & 1.723 & 0,81 \\
\hline II & $\begin{array}{c}70 \% \text { de agregado natural e } \\
\text { de } 30 \% \text { SCDP }\end{array}$ & 2,179 & 1,04 \\
\hline III & $\begin{array}{l}68 \% \text { de agregado natural, } \\
\text { de } 30 \% \text { SCDP e de } 2 \% \text { cal }\end{array}$ & 2.758 & 1,13 \\
\hline
\end{tabular}

O ensaio de fadiga foi realizado por compressão diametral à tensão controlada, onde a carga é aplicada na frequência de $1 \mathrm{~Hz}$ através de um equipamento pneumático, conforme procedimento descrito em Bernucci et al. (2007). Foram adotados os percentuais de 50, 40 e 30\% de RT para a realização do ensaio de vida de fadiga. Para cada nível de tensão,o ensaio foi realizado em três CPs. A Figura 5 apresenta os resultados encontrados.

Através das retas apresentadas na Figura 5, é possível observar que as misturas que contêm SCDP (Misturas II e III) apresentam comportamento superior (maior número de aplicação de ciclos de carga antes da ruptura) para valores baixos de tensões, se comparadas à Mistura I. Espera-se que, para solicitações de tensões baixas, as misturas com SCDP tenham um desempenho superior com relação à fadiga. A Mistura II, apesar de ter uma inclinação próxima a que foi encontrada para a Mistura III, tem resultados de vida de fadiga inferiores se comparados aos resultados encontrados para a Mistura II. Os resultados descritos são apenas comparativos devido as limitações desse tipo de ensaio e ao fato das misturas apresentarem diferentes valores de MR. Normalmente, para este tipo de ensaio conduzido a tensão controlada, materiais mais rígidos apresentam vida de fadiga superior. $O$ que não necessariamente representa uma propriedade do material e sim um efeito da metodologia do ensaio nos resultados do mesmo.

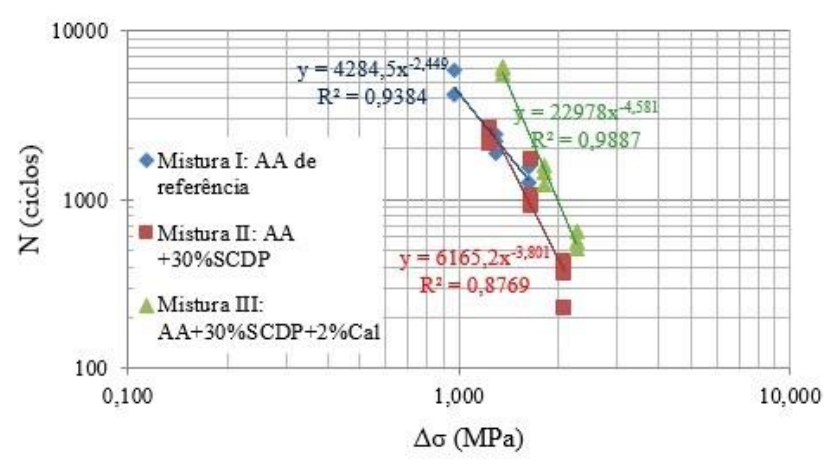

Figura 5. Resultados do ensaio de vida de fadiga

\subsection{Viabilidade ambienta}

A viabilidade ambiental foi estimada em termos dos impactos promovidos pela a adição de SCDP a mistura asfáltica através de experimentos de dissolução e de lixiviação. A Tabela 7 mostra os resultados destes ensaios para as misturas analisadas neste trabalho. Para a Mistura I, a concentração de ferro (Fe) foi acima da permitida, logo, a mistura foi classificada como resíduo não inerte, Classe IIA. Para a Mistura II, os valores de alumínio (Al), de ferro $(\mathrm{Fe})$ e de manganês (Mn) apresentaram-se acima do VMP. Já para a Mistura III, apenas para os fenóis foram encontrados valores acima do VMP. Ressalta-se que esse resultado (quantidade de fenóis totais encontrada na amostra analisada) pode ter sido influenciada pelo próprio ligante asfáltico presente na amostra e não somente pelo uso do SCDP. Portanto, as três misturas foram classificadas como Classe IIA, sendo estas consideradas não inertes.

Alguns parâmetros hidroquímicos foram analisados no Laboratório de Avaliação de Contaminantes Orgânicos/Labomar/UFC utilizando-se também como referências as NBR 10.005:2004 e 10.006:2004, assim como a Resolução CONAMA 357/2005 que controlam o lançamento no ambiente de poluentes, aferindo quanto ao lançamento em níveis de risco ou perigosos para a biota. Um estudo prévio foi realizado para avaliar a qualidade da água lixiviada, em contato com as misturas analisadas conforme a norma NBR 10.006:2004.

A análise de sulfato apresenta como propriedades físico-químicas baixa toxicidade e alta solubilidade em água. No entanto, a sua problemática é quando este sofre redução, em ambientes anaeróbicos, que são ideais para o desenvolvimento de bactérias redutoras, formando sulfetos que podem ser prejudiciais para a biota local, por estes alterarem o equilíbrio do ambiente (Silva et al., 2000). Segundo a Portaria 518/2004 do Ministério da Saúde e a Resolução CONAMA 357/2005, a concentração máxima 
Tabela 7. Avaliação ambiental das misturas asfálticas I,II e III

\begin{tabular}{|c|c|c|c|c|c|c|c|c|}
\hline \multirow{4}{*}{ Parâmetro } & \multirow{2}{*}{\multicolumn{3}{|c|}{$\frac{\text { Solubilizado }(\mathrm{mg} / \mathrm{L}) 10.005}{\text { Resultados }}$}} & \multirow{2}{*}{\multicolumn{5}{|c|}{$\begin{array}{c}\text { Lixiviado }(\mathrm{mg} / \mathrm{L}) 10.0006 \\
\text { Resultados } \\
\end{array}$}} \\
\hline & & & & & & & & \\
\hline & $\begin{array}{c}\text { Mistura } \\
\text { I }\end{array}$ & $\begin{array}{l}\text { Mistura } \\
\text { II }\end{array}$ & $\begin{array}{c}\text { Mistura } \\
\text { III }\end{array}$ & VMP & $\begin{array}{c}\text { Mistura } \\
\text { I }\end{array}$ & $\begin{array}{c}\text { Mistura } \\
\text { II }\end{array}$ & $\begin{array}{l}\text { Mistura } \\
\text { III }\end{array}$ & VMP \\
\hline & \multicolumn{8}{|c|}{ INORGÂNICOS } \\
\hline Alumínio (Al) & 0,083 & 0,28 & 0,08 & 0,20 & - & - & - & - \\
\hline Arsênio (As) & $<0,0030$ & $<0,0030$ & $<0,001$ & 0,01 & $<0,0030$ & $<0,0030$ & $<0,04$ & 1 \\
\hline Bário (Ba) & $<0,0630$ & $<0,0630$ & 0,18 & 0,70 & 0,27 & 0,28 & 0,9 & 70 \\
\hline Cádmio (Cd) & $<0,0040$ & $<0,0040$ & $<0,003$ & 0,005 & $<0,0080$ & $<0,0080$ & $<0,003$ & 0,5 \\
\hline Chumbo $(\mathrm{Pb})$ & $<0,0060$ & $<0,0060$ & $<0,002$ & 0,01 & $<0,0630$ & 0,15 & $<0,03$ & 1 \\
\hline Cianeto $(\mathrm{CN})$ & $<0,0500$ & $<0,0500$ & 0,049 & 0,07 & - & - & - & - \\
\hline Cloreto $(\mathrm{Cl})$ & 1,500 & 2,5 & 5,14 & 250 & - & - & - & - \\
\hline Cobre $(\mathrm{Cu})$ & $<0,0250$ & $<0,0250$ & 0,03 & 1 & - & - & - & - \\
\hline Crômio total $(\mathrm{Cr})$ & $<0,0050$ & $<0,0500$ & 0,002 & 0,05 & $<0,0100$ & $<0,1000$ & 0,003 & 5 \\
\hline Fenóis totais & $<0,0030$ & $<0,0030$ & 0,014 & 0,010 & $<0,0030$ & $<0,0030$ & - & 0,01 \\
\hline Ferro $(\mathrm{Fe})$ & 0,32 & 0,38 & 0,04 & 0,30 & - & - & - & - \\
\hline Fluoreto $(\mathrm{F})$ & 0,27 & 0,23 & 0,17 & 1,5 & $<0,0200$ & $<0,2000$ & 0,15 & 150 \\
\hline Manganês (Mn) & $<0,0150$ & 0,13 & $<0,0001$ & 0,1 & - & - & - & - \\
\hline Mercúrio (Hg) & $<0,0006$ & $<0,0006$ & $<0,0001$ & 0,001 & $<0,0006$ & $<0,0006$ & 0,0006 & 0,1 \\
\hline Nitrato $(\mathrm{N})$ & $<0,2000$ & 0,39 & 0,99 & 10 & - & - & - & - \\
\hline Prata (Ag) & $<0,0120$ & 0,012 & $<0,003$ & 0,05 & $<0,0120$ & $<0,0120$ & $<0,003$ & 5 \\
\hline Selênio (Se) & $<0,0090$ & 0,009 & $<0,002$ & 0,01 & $<00090$ & $<0,0090$ & $<0,05$ & 1 \\
\hline Sódio $(\mathrm{Na})$ & 3,31 & 7,59 & 2,01 & 200 & - & - & - & - \\
\hline Sulfato $\left(\mathrm{SO}_{4}{ }^{2-}\right)$ & $<10,0000$ & $<10,0000$ & 4,54 & 250 & - & - & - & - \\
\hline Surfactantes & $<0,1000$ & $<0,1000$ & 0,082 & 0,5 & - & - & - & - \\
\hline Zinco (Zn) & 0,023 & 0,082 & $<0,006$ & 5 & - & - & - & - \\
\hline \multirow[t]{2}{*}{$\mathrm{pH}$ final } & 7,7 & 7,6 & 10,9 & - & 4,8 & 5,4 & 4,99 & - \\
\hline & \multicolumn{7}{|c|}{ ORGÂNICOS } & \\
\hline Naftaleno & - & - & - & - & $<0,001$ & $<0,0001$ & - & - \\
\hline Acenaftileno & - & - & - & - & 0,0003 & 0,0004 & - & - \\
\hline Acenafteno & - & - & - & - & $<0,0001$ & 0,0003 & - & - \\
\hline Fluoreno & - & - & - & - & $<0,0001$ & $<0,0001$ & - & - \\
\hline Fenantreno & - & - & - & - & 0,0004 & 0,0006 & - & - \\
\hline Antraceno & - & - & - & - & $<0,0001$ & 0,0003 & - & - \\
\hline Fluoranteno & - & - & - & - & $<0,0001$ & 0,0002 & - & - \\
\hline Pireno & - & - & - & - & $<0,0001$ & $<0,0001$ & - & - \\
\hline Benzo(a)antraceno & - & - & - & - & $<0,0001$ & $<0,0001$ & - & - \\
\hline Criseno & - & - & - & - & $<0,0001$ & $<0,0001$ & - & - \\
\hline Benzo(b)fluoranteno & - & - & - & - & $<0,0001$ & $<0,0001$ & - & - \\
\hline Benzo(k)fluoranteno & - & - & - & - & $<0,0001$ & $<0,0001$ & - & - \\
\hline Benzo(a)pireno & - & - & - & - & $<0,0001$ & $<0,0001$ & - & 0,07 \\
\hline Indeno $(1,2,3$ - c.d $)$ & - & - & - & - & $<0,0001$ & $<0,0001$ & - & - \\
\hline Pireno & - & - & - & - & $<0,0001$ & 0,0002 & - & - \\
\hline Dibenzo(a.h) & - & - & - & - & $<0,0001$ & 0,0002 & - & - \\
\hline Antraceno & - & - & - & - & - & - & - & - \\
\hline Benzo(g.h.i)perileno & - & - & - & - & 0,0002 & 0,0002 & - & - \\
\hline Benzeno & - & - & - & - & - & - & - & $<0,0001$ \\
\hline Etilbenzeno & - & - & - & - & - & - & - & $<0,0001$ \\
\hline Tolueno & - & - & - & - & - & - & - & $<0,0001$ \\
\hline Xileno & - & - & - & - & - & - & - & $<0,0001$ \\
\hline
\end{tabular}

permitida de sulfato em águas para consumo humano é de até $250 \mathrm{mg} / \mathrm{L}$ (ppm). Segundo a Portaria 518/2004 do Ministério da Saúde e a Resolução CONAMA 357/2005, a concentração máxima permitida de sulfato em águas para consumo humano é de até $250 \mathrm{mg} / \mathrm{L}$ (ppm). Os resultados obtidos para as diferentes amostras e experimentos (dissolução e lixiviação) não ultrapassaram a ordem da dezena (Figura 6). No experimento de dissolução, as amostras do Branco e da Mistura I geraram valores de concentrações inferiores ao Limite de Detecção $(0,86 \mathrm{mg} / \mathrm{L})$. Para as Misturas II e III foram obtidos valores de $2,8 \mathrm{mg} / \mathrm{L}$ e $1,2 \mathrm{mg} / \mathrm{L}$ de sulfato, respectivamente. No experimento de lixiviação esse valores variaram de 13,52 $\mathrm{mg} / \mathrm{L}$ para a Mistura I e 23,57 mg/L para a Mistura III, e concentração inferior ao limite de detecção para a Mistura
II. Com esse comportamento as misturas podem ser aplicadas como resíduos para a pavimentação devido à ausência e à baixa concentração de sulfato nas amostras avaliadas.

Condutividade ou condutância específica de uma amostra é a medida de sua capacidade de conduzir corrente elétrica. Geralmente, a análise da condutividade é aplicada para avaliar o grau de mineralização de uma água, contribuindo para o estudo do efeito de diversos íons sobre o equilíbrio químico e no efeito fisiológico sobre as plantas ou animais, relacionando assim a concentração de matéria iônica dissolvida. Os íons diretamente responsáveis pelos valores de condutividade elétrica em águas são os chamados macronutrientes (cálcio, magnésio, potássio, sódio, carbonato, sulfato, etc). Para a análise do teste de 
condutividade, os resultados nesse estudo foram avaliados

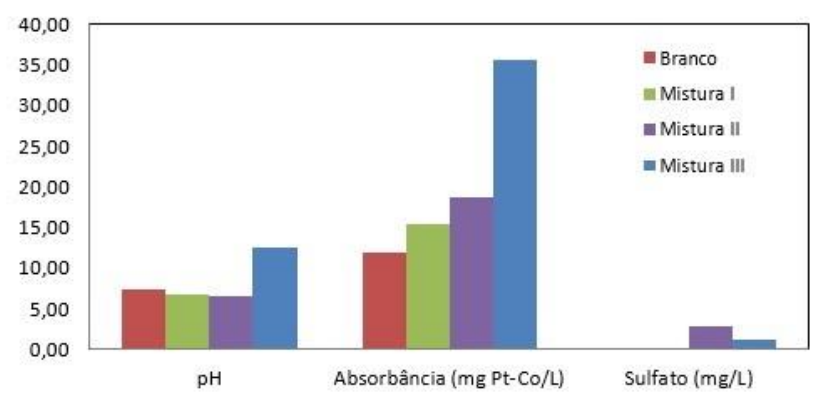

Figura 6. Resultados das análises de $\mathrm{pH}$, cor aparente e concentração de sulfato

de forma qualitativa com o intuito de observar a presença de íons em solução que promovesse a alteração na composição do conteúdo lixiviado. Os resultados obtidos foram expressivos entre as amostras, com uma variação de $4,13 \mu \mathrm{S} . \mathrm{cm}^{-1}$ para a amostra Branco, $8,54 \mu \mathrm{S} . \mathrm{cm}^{-1}$ para a Mistura I, $18,81 \mu \mathrm{S} . \mathrm{cm}^{-1}$ para Mistura II e de $856,50 \mu \mathrm{S} . \mathrm{cm}^{-}$ ${ }^{1}$ para a Mistura III, no experimento de dissolução. Já para o experimento de lixiviação,os resultados variaram de $36,22 \mu{\mathrm{S} . \mathrm{cm}^{-1}}$ para a Mistura I, $48,59 \mu \mathrm{S} . \mathrm{cm}^{-1}$ para a Mistura

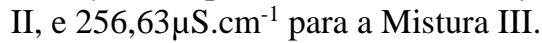

A diferença entre os valores de condutividade elétrica para as amostras evidencia que quanto maior for a quantidade/presença de compostos ionizáveis na mistura, maior deve ser a condutância elétrica em meio aquoso. Com relação a diferença entre os experimentos, pode-se admitir que, apesar da compactação das amostras utilizadas para o experimento lixiviado, os compostos hidrossolúveis contidos nas amostras foram carreados, não ocorrendo similar comportamento com as amostras do experimento de dissolução que sofreram um equílibrio estático com os agregados da mistura no tanque reacional. Já para a Mistura III, o comportamento foi peculiar entre os experimentos. Por ser a única mistura a conter cal na sua composição, o resultado apresentado foi de redução da liberação dos compostos ionizáveis na solução. Esse resultado fortalece o conceito de que a cal se comporta como agente encapsulante.

$\mathrm{O} \mathrm{pH}$, utilizado para a avaliação da qualidade da água, representa as concentrações dos íons $\mathrm{H}^{+}$e $\mathrm{OH}^{-}$ presente no meio, indicando a alcalinidade, a acidez ou a neutralidade do mesmo. $\mathrm{O}$ pH é usado como padrão de potabilidade, sendo necessário as águas para abastecimento público apresentar valores entre 6,0 e 9,5 (Portaria 518/2004). Este constitui-se, também, em padrão de emissão de esgotos e de efluentes líquidos industriais, o qual deve estar entre 5,0 e 9,0 para o lançamento na rede pública, seguida de estação de tratamento de esgotos; e para as águas doces de classe, 1, 2, 3 e 4, o pH deve estar entre 6,0 e 9,0 (CONAMA 357/2005). Todos os resultados desse estudo foram considerados satisfatórios (Figura 6). Em ambos os experimentos admitiu-se um aumento significativo do $\mathrm{pH}$ para a Mistura III, devido a formação de hidróxido de cálcio na solução aquosa. É importante salientar que existe uma forte tendência deste material liberar íons de caráter básicos, já que a Mistura III contém cal.

A cor aparente é o grau de redução de intensidade que a luz sofre ao atravessar um meio líquido, devido a presença de sólidos dissolvidos, principalmente para material em estado coloidal orgânico (ácidos húmico e fúlvico) e inorgânico (óxidos de ferro e de manganês provenientes do solo). As análises foram realizadas utilizando um colorímetro (espectrofômetro portátil) que expressa os resultados em absorbância (mgPt-Co/L). Segundo a portaria do Ministério da Saúde 518/2004, o valor máximo permitido da cor aparente é de $15 \mathrm{uH}(1 \mathrm{uH}=1 \mathrm{mgPt}-\mathrm{Co} / \mathrm{L}=$ 1UC). Já na CONAMA 357/2005, dependendo da classe de água, a variação aceitável pode atingir no máximo $75 \mathrm{mgPt}-$ $\mathrm{Co} / \mathrm{L}$. Os resultados obtidos entre os experimentos desse estudo na análise de cor aparente atingiu como valor máximo 35,60mg PT-Co/L para a Mistura III (experimento de dissolução), um valor mediano considerando a CONAMA 357/2005, mas que não compromete a qualidade da água. Os resultados evidenciam a baixa alteração no âmbito visual nas amostras, tanto no experimento de dissolução como no experimento de lixiviação (Figura 6).

Óleos e graxas são substâncias orgânicas de origem mineral, vegetal ou animal, tais como, hidrocarbonetos, gorduras, ésteres, entre outros. São raramente encontrados em águas naturais, sendo o seu âmbito mais comum proveniente de despejos e de resíduos industriais, de esgotos domésticos, de efluentes de oficinas mecânicas, de postos de gasolina, de estradas e de vias públicas. A presença de material graxo nos corpos hídricos, além de ocasionar problemas estéticos, reduz a área de contato entre a superfície da água e o ar atmosférico, impedindo, a entrada do oxigênio da atmosfera para a água promovendo alterações no ecossistema aquático. Para a legislação brasileira, a recomendação é de que os óleos e as graxas sejam virtualmente ausentes para os corpos d’água nas diferentes classes, ou seja, o critério avaliado se limita apenas no âmbito qualitativo. Ponderando os resultados obtidos nesse estudo, observou-se que, para todas as amostras, os valores não ultrapassaram $0,04 \mathrm{mg} / \mathrm{L}$, sendo considerados assim como não significativos, ou seja, as misturas com diferentes tipos de composição não evidenciaram alterações consideradas plausíveis para um risco ambiental no que diz respeito a presença de óleos e de graxas.

Para a avaliação do risco potencial de contaminação por compostos orgânicos foi utilizado os Valores Máximos Permitidos (VMPs) (CONAMA 357/2005). Ocorreu uma diferença entre o estudo de lixiviação e o estudo de percolação (Tabela 8). Para ambos os estudos de lixiviação e de percolação, os compostos menores e de menor massa molecular, da classe dos Compostos Orgânicos Voláteis (COVs), tais como: benzeno, cloreto de vinila, cloroformio, 1,2-dicloetano, 1,1-dicloeteno, tetracloroeteno, tetracloreto de carbono e tricloroeteno não foram detectados $(<2$ $\mathrm{ng} / \mathrm{mL}$ ). A ausência dessses compostos ou sua concentração em níveis traços, se deve ao fato de serem bastantes voláteis, assim o seu escape pode ocorrer nas etapas do processo de produção (Brantley e Townsend, 1999; Wang et al., 2001).

Para as substâncias da classe dos Compostos Orgânicos Semi-Voláteis (COSVs) (CONAMA 357), como exemplo: benzo(a)antraceno; criseno; benzo(b)fluoranteno; benzo(k)fluoranteno, benzo(a)pireno; Indeno[1,2,3cd]fluoranteno e dibenzo(a,h)antraceno, que são insolúveis em água e apresentam volatilidades reduzidas, foram verificados nos Experimentos de Percolação (Mistura II) e nos Experimentos de Dissolução (Mistura I e II). Os HPAs da Resolução CONAMA 357 foram ausentes nas Misturas 
Tabela 8. Resultados dos níveis $(\mathrm{ng} / \mathrm{mL})$ dos compostos orgânicos investigados

\begin{tabular}{|c|c|c|c|c|c|c|c|}
\hline \multirow{2}{*}{ Substâncias } & \multicolumn{3}{|c|}{ Experimento de percolação } & \multicolumn{3}{|c|}{ Experimento de dissolução } & \multirow[t]{2}{*}{$\begin{array}{c}\text { VMP } \\
(\mathrm{ng} / \mathrm{mL})\end{array}$} \\
\hline & $\begin{array}{c}\text { Mistura } \\
\text { I }\end{array}$ & $\begin{array}{c}\text { Mistura } \\
\text { II }\end{array}$ & $\begin{array}{c}\text { Mistura } \\
\text { III }\end{array}$ & $\begin{array}{c}\text { Mistura } \\
\text { I }\end{array}$ & $\begin{array}{c}\text { Mistura } \\
\text { II }\end{array}$ & $\begin{array}{c}\text { Mistura } \\
\text { III }\end{array}$ & \\
\hline \multicolumn{8}{|c|}{ Compostos orgânicos voláteis } \\
\hline Benzeno & $<2,0$ & $<2,0$ & $<2,0$ & $<2,0$ & $<2,0$ & $<2,0$ & 5 \\
\hline Cloreto de Vinila & $<2,0$ & $<2,0$ & $<2,0$ & $<2,0$ & $<2,0$ & $<2,0$ & - \\
\hline Clorofórmio & $<2,0$ & $<2,0$ & $<2,0$ & $<2,0$ & $<2,0$ & $<2,0$ & - \\
\hline 1,2-dicloroeteno & $<2,0$ & $<2,0$ & $<2,0$ & $<2,0$ & $<2,0$ & $<2,0$ & 10 \\
\hline 1,1-dicloroeteno & $<2,0$ & $<2,0$ & $<2,0$ & $<2,0$ & $<2,0$ & $<2,0$ & 3 \\
\hline Tetracloroeteno & $<2,0$ & $<2,0$ & $<2,0$ & $<2,0$ & $<2,0$ & $<2,0$ & - \\
\hline Tetracloeto de Carbono & $<2,0$ & $<2,0$ & $<2,0$ & $<2,0$ & $<2,0$ & $<2,0$ & - \\
\hline Tricloroeteno & $<2,0$ & $<2,0$ & $<2,0$ & $<2,0$ & $<2,0$ & $<2,0$ & - \\
\hline \multicolumn{8}{|c|}{ Compostos orgânicos semi-voláteis } \\
\hline Naftaleno & 1,56 & 6,83 & 1,11 & 71,13 & 83,17 & 25,69 & - \\
\hline Acenaftileno & 3,36 & 1,80 & 1,84 & 17,03 & 17,10 & 7,34 & - \\
\hline Acenafteno & 3,82 & 1,02 & 1,89 & 16,25 & 26,17 & 2,95 & - \\
\hline Fluoreno & 4,13 & 12,41 & 3,42 & 8,14 & 24,22 & 4,66 & - \\
\hline Fenantreno & 4,62 & 2,29 & 3,68 & 5,53 & 19,12 & 3,72 & - \\
\hline Antraceno & 4,78 & 2,37 & 0,40 & 9,42 & 35,87 & 5,29 & - \\
\hline Fluoranteno & $<0,03$ & 0,68 & $<0,03$ & 3,87 & 12,54 & 3,85 & - \\
\hline Pireno & $<0,03$ & 1,00 & $<0,03$ & 5,01 & 33,79 & 0,94 & - \\
\hline Benzo[a]antraceno & $<0,03$ & 0,22 & $<0,03$ & 0,24 & 1,46 & $<0,03$ & 0,05 \\
\hline Criseno & $<0,03$ & 0,37 & $<0,03$ & 0,19 & 3,90 & $<0,03$ & 0,05 \\
\hline Benzo[b]fluoranteno & $<0,03$ & 0,68 & $<0,03$ & 0,36 & 0,59 & $<0,03$ & 0,05 \\
\hline Benzo[k]fluoranteno & $<0,03$ & 0,55 & $<0,03$ & 0,48 & 0,13 & $<0,03$ & 0,05 \\
\hline Benzo[a]pireno & $<0,03$ & 0,58 & $<0,03$ & 0,09 & 1,96 & $<0,03$ & 0,05 \\
\hline Indeno[1,2,3-cd]fluoranteno & $<0,03$ & $<0,03$ & $<0,03$ & $<0,03$ & $<0,03$ & $<0,03$ & 0,05 \\
\hline Dibenzo[a.h]antraceno & $<0,03$ & $<0,03$ & $<0,03$ & $<0,03$ & $<0,03$ & $<0,03$ & 0,05 \\
\hline Benzo[g.h.i]perileno & $<0,03$ & $<0,03$ & $<0,03$ & $<0,03$ & $<0,03$ & $<0,03$ & - \\
\hline$\Sigma$ HPAs & 22,27 & 30,79 & 12,34 & 137,73 & 260,02 & 54,45 & - \\
\hline$\Sigma$ HPAs de 2-3 anéis & 22,27 & 27,39 & 12,34 & 131,35 & 218,18 & 53,51 & - \\
\hline$\Sigma$ HPAs de 4 e 5 anéis & 0,00 & 3,40 & 0,00 & 6,38 & 41,84 & 0,94 & - \\
\hline
\end{tabular}

I e III (Experimentos de Percolação) e Mistura III (Experimentos de Dissolução) (Tablea 8). Na Mistura III, em ambos os Experimentos, os níveis dos HPAs da Resolução CONAMA 357 foram abaixo dos níveis de detecção $(<0,03 \mathrm{ng} / \mathrm{mL})$. Isso é um forte indicativo de que a cal adicionada pode estar atuando como um agente encapsulante para os respectivos HPAs.

Outros HPAs, que não estão presentes na resolução CONAMA 357, foram também estudados e os níveis dos mesmos estão sumarizados na Tabela 8 . Conforme pode ser verificado no Experimento de Percolação, como também no Experimento de Dissolução, ocorre uma tendência, com exceções mínimas. A Mistura II apresenta valores maiores do que aqueles encontrados para a Mistura I, seguidos dos valores encontrados para a Mistura III. Essa tendência era esperada, uma vez que a Mistura II é enriquecida de hidrocarbonetos oriundos de processos petroquímicos, os quais se juntam aos níveis existentes na Mistura I. Os níveis menores na Mistura III, são explicados devido a possibilidade do mesmo estar agindo como encapsulante. Essa tendência pode ser verificada também em termos de somatório dos níveis de HPAs ( $\Sigma$ HPAs). O $\Sigma$ HPAs de 2-3 anéis aromáticos foi de 5 a 9 vezes superior aos níveis do $\Sigma$ HPAs de 4-6 anéis aromáticos em ambos os estudos. Essa abundância dos HPAs de menor massa molecular (2 e 3 anéis aromáticos) é explicada em virtude da maior dissolução por essas substâncias em água, uma vez que a dissolução é bem menor para os HPAs de maior massa molecular (4 a 6 anéis).
Em termos de comparação entre os Experimentos de Percolação e de Dissolução, verifica-se que no Experimento de Dissolução os níveis são de 4 a 9 vezes maiores. Isso é esperado, uma vez que a superfície de contato e o tempo de equilíbrio são maiores neste experimento se comparado ao Experimento de Percolação (Tabela 8). Brantley e Townsend (1999) mencionam que a coluna de mistura asfáltica compactada é hidrofóbica, criando caminhos preferenciais, os quais diminuem a eficiência da dissolução devido a diminuição da superficie de contato. No material compactado (Experimento de Percolação), as substância investigadas estão mais encapsuladas, bem como o tempo de contato com a fase solvente (água) é menor e menos eficiente, uma vez que a maioria dos HPAs apresenta moderada a baixa solubilidade. Segundo Brandt e Groot (2001), a lixiviação dos constituintes do liganteasfáltico é menos eficiente para os HPAs de maior massa molecular, em virtude dos mesmos serem insolúveis em água, dificultando o seu lançamento no ambiente. Brantley e Townsend (1999), em estudos de percolação em coluna asfáltica, reportam que nos primeiros volumes de eluições, os níveis de HPAs apresentam altos riscos, entretanto, após a eluição por completo, os níveis ficam abaixo dos limites de detecção, não oferecendo risco ao ambiente. Desta forma, os níveis traços ou a ausência de HPAs no Experimento de Percolação são esperados.

A $\Sigma$ HPAs em relação a massa do material estudado (SCDP) foi de 286,02ng/g no Experimento de Dissolução. A priore esses níveis são baixosse comparados a estudos de avaliação dos níveis de HPAs em sedimentos em ambientes 
aquáticos (Zheng e Richardson, 1999; Venturini e Tommasi, 2004; Macdonald et al., 2005; Medeiros et al., 2005; Vane et al., 2007; Cavalcante et al., 2010), oriundos da contaminação pela queima de combustíveis fósseis. Considerando que um revestimento padrão pode consumir em torno de $109 \mathrm{~kg}$ pormetro quadrado de material asfáltico (mistura asfáltica com densidade aparente de 2,180 e revestimento com $5 \mathrm{~cm}$ de espessura), esses níveis podem causar impacto, principalmente com a existência de um ambiente aquático nas proximidades do pavimento. Ahrens e Depree (2010) atribuem a alta concentração de HPAs em sedimento de córregos e estuários em Auckland, Nova Zelândia, aos trinta anos de uso de carvão em serviços de pavimentação em áreas urbanas. Partículas de ligante asfáltico provenientes da rodovia, granulometria $>620 \mu \mathrm{m}$, foram encontradas no sedimento do rio Thur, França. Essas partículas foram lançadas nos ambientes aquáticos através de processos de abrasão mecânica e de transporte superficial (Faure et al., 2000).

Nesse estudo foram realizados ensaios para a obtenção de parâmetros de metais pesados para as misturas avaliadas (Tabela 9). Para as Misturas I e II os valores ficaram dentro do aceitável de acordo com a Resolução CONAMA 357/2005. Para a Mistura III os parâmetros de Alumínio e Cobre ficaram acima do VMP.

Tabela 9. Resultados de metais pesados para as misturas avaliadas

\begin{tabular}{lcccc}
\hline Parâmetro & $\begin{array}{c}\text { Mistura } \\
\text { I }\end{array}$ & $\begin{array}{c}\text { Mistura } \\
\text { II }\end{array}$ & $\begin{array}{c}\text { Mistura } \\
\text { III }\end{array}$ & $\begin{array}{c}\text { VMP } \\
(\mathbf{m g} / \mathbf{L})\end{array}$ \\
\hline Alumínio (Al) & $<0,05$ & $<0,05$ & 0,41 & 0,1 \\
Arsênio (As) & 0,004 & 0,002 & 0,002 & 0,01 \\
Bário (Ba) & 0,01 & 0,02 & 0,02 & 0,7 \\
Cádmio (Cd) & $<0,0005$ & $<0,0005$ & $<0,0005$ & 0,001 \\
Chumbo (Pb) & $<0,002$ & $<0,002$ & $<0,002$ & 0,01 \\
Cianeto (CN) & 0,0012 & 0,0027 & 0,0023 & 0,005 \\
Cloreto (Cl) & 1,58 & 1,79 & 3,32 & 250 \\
Cobre (Cu) & $<0,005$ & $<0,005$ & 0,02 & 0,009 \\
Crômio total & 0,01 & 0,01 & 0,02 & 0,05 \\
Ferro (Fe) & $<0,002$ & $<0,002$ & $<0,002$ & 0,3 \\
Fluoreto (F) & 0,54 & 0,14 & $<0,05$ & 1,4 \\
Manganês (Mn) & 0,03 & 0,05 & 0,007 & 0,1 \\
Mercúrio (Hg) & $<0,0001$ & $<0,0001$ & $<0,0001$ & 0,0002 \\
Nitrato (N) & 0,18 & 0,24 & 0,6 & 10 \\
Prata (Ag) & $<0,005$ & $<0,005$ & $<0,005$ & 0,01 \\
Selênio (Se) & $<0,002$ & $<0,002$ & $<0,002$ & 0,01 \\
Sulfato (SO42-) & 9,54 & 5,36 & 11,3 & 250 \\
Zinco (Zn) & $<0,005$ & 0,01 & $<0,005$ & 0,18 \\
\hline
\end{tabular}

\section{CONSIDERAÇÕES FINAIS}

Neste trabalho foi verificada a viabilidade técnica e ambiental referente à utilização de SCDP como constituinte de misturas asfálticas para serviços de pavimentação. Foram produzidas três misturas asfálticas, uma contendo apenas agregados naturais, outra contendo $70 \%$ de agregados naturais e $30 \%$ de SCDP e uma terceira contendo $68 \%$ de agregados naturais, $30 \%$ de SCDP e $2 \%$ de cal. Foi observado que a correta caracterização do SCDP é relevante para que se possa realizar a dosagem e a caracterização mecânica das misturas asfálticas com utilização deste resíduo em sua composição. Outro ponto a ser ressaltado é a dificuldade de se obter amostras das misturas contendo SCDP dentro da faixa de variação adequada para $\mathrm{Vv}$, provavelmente devido a heterogeneidade do resíduo quanto aos tipos e aos percentuais de contaminantes. A presença da cal gerou uma diminuição no número de CPs com valores de percentual de Vv fora da faixa de aceitação do DNIT, o que pode contribuir para a viabilidade do uso do resíduo. A utilização do SCDP na composição de misturas asfálticas contribuiu para a diminuição do teor de ligante asfáltico de projeto virgem incorporado nas misturas em torno de $40 \%$.As Misturas II e III, contendo o resíduo em sua composição, apresentaram resultados de MR e RT superiores à Mistura I, que não contém resíduo em sua composição. Além disso, os resultados do ensaio de fadiga indicam que as misturas contendo SCDP apresentam um melhor comportamento quando baixos valores de tensões são considerados.

O uso do SCDP em pavimentos asfálticos é uma alternativa viável, já que, a incorporação do material às misturas asfálticas é uma opção de destinação que reduz os impactos ambientais, pois os ensaios de solubilização e de lixiviação para o SCDP o classificaram como perigoso, porém as misturas asfálticas contendo SCDP foram consideradas não perigosas(NBR - 10.004:2004). Misturas contendo este resíduo podem ser destinadas à RBVT. Além disso, para os parâmetros presença de sulfato e concentração dos HPAs, foi possível observar o potencial de encapsulamento da cal. Destaca-se o potencial de uso da Mistura III (com SCDP e cal em sua composição) a partir dos resultados mecânicos e ambientais encontrados para esse material. Todavia, os níveis dos metais pesados (alumínio e cobre) encontrados para essa mistura foram acima do VMP o que indica a necessidade de investigação mais aprofundada ou o uso de outros percentuais de SCDP na composição destas misturas asfálticas para uso em serviços de pavimentação.

Outros fatores importantes a serem ressaltados com relação ao uso do SCDP em misturas asfálticas são: a diminuição do uso de recursos naturais não renováveis e a diminuição do custo da pavimentação asfáltica. Através do estudo de viabilidade ambiental, pôde-se comprovar que não existe diferença significativa entre ambas as misturas (com e sem o resíduo), sendo assim, o SCDP não é o responsável isolado por agregar a característica perigosa à mistura.

\section{AGRADECIMENTOS}

Os autores agradecem ao $\mathrm{CNPq}$ pelas bolsas concedidas ao primeiro e aos dois últimos autores, à CAPES pela bolsa concedida ao segundo autor e a Petrobras pelo fornecimento dos materiais utilizados.

\section{REFERÊNCIAS}

Ahrens, M.J.; Depree,V.V. (2010) A Source Mixing Model to Apportion PAHs from Coal Tar and Asphalt Binders in Street Pavements and Urban Aquatic Sediments. Chemosphere 81. DOI:10.1016/ j.chemosphere.2010.08.030

Aldigueri, D.R, Parente, E.B., Soares, J.B. (2004) Estudo da Aplicabilidade de Solo Contaminado por Derivados de Petróleo como Material para Revestimento de Vias de Baixo Volume de Tráfego. XVII ANPET. Florianópolis, SC.

Antunes, F.F.L, Castelo Branco, V.T.F., Soares, J.B. (2010) Avaliação dos Impactos Ambientais Causados pela Utilização de 
Rejeitos em Misturas Asfálticas. 20o Encontro de Asfalto. Rio de Janeiro, RJ.

Bernucci, L.B.; Motta, L.M.G.; Ceratti, J.A.P.; Soares, J.B. (2007) Pavimentação Asfáltica: Formação Básica para Engenheiros. 1. ed. Rio de Janeiro, RJ.

Bezerra, M.F., Patrício L.S., Filho F.J.N.S., Oliveira A.H.B, Cavalcante R.M. (2012) Experimento Didático Abordando a Importância da Validação Metodológica no Estudo da Química do Sulfato no Meio Ambiente.

Brantley, A.S.; Townsend, T.S. (1999) Leaching of Pollutants from Reclaimed Asphalt Pavement. Environmental Engineering Science, 16. DOI: 10.1089/ees.1999.16.105

Cavalcante, F.C.I.T. (2010) Investigação do Emprego de Solo Contaminado por Derivados de Petróleo em Camadas Granulares de Pavimento. Universidade Federal do Ceará. Monografia. Fortaleza, CE.

Cavalcante R.M., Sousa F.W., Nascimento R.F., Silveira E.R., Freire G.S.S. (2009) The Impact of Urbanization on Tropical Mangroves (Fortaleza, Brazil): Evidence from PAH Distribution in Sediments. J Environ Manage 91. DOI:10.1016/j.jenvman.2009.08.020

CONAMA (2005) Conselho Nacional do Meio Ambiente . Resolução n $^{\circ} 357$, de 17 de março de 2005. Ministério do Meio Ambiente, 23p.

Cordeiro, J.F.S. (2007) Estabilização Química e Solidificação do Resíduo Oleoso Gerado nas Atividades de E\&P de Petróleo, com Solo para Uso em Camadas de Bases elou Sub-Bases de Pavimentos Rodoviários. Dissertação de Mestrado. Universidade Federal de Campina Grande. Campina Grande, PB.

Esteves, F.A. (1998) Fundamentos de Limnologia. $2^{\text {a }}$ Ed. Rio de Janeiro Interciência/ FINEP, 602 p.

Farias, E.R. (2005) A Utilização de Misturas Solo/Cinza Pesada na Pavimentação - Análise de Aspectos de Comportamento Mecânico e Ambiental. Universidade Federal de Santa Catarina. Dissertação de Mestrado. Florianópolis, SC.

Francisco, J.L., França, K.C. (2007) Dossiê Técnico: Métodos de Tratamento de Resíduos de Petróleo. Rede de Tecnologia do Rio de Janeiro - REDETEC. Rio de Janeiro, RJ.

Faure, P.; Landais, P.; Schlepp, L.; Michels, R. (2000) Evidence for Diffuse Contamination of River Sediments by Road Asphalt Particles. Environmental Science and Technology 34. DOI:10.1021/es9909733

Heineck, K.L., Consoli N.C, Cruz, R.C., Knop, A. (2007) Encapsulamento de um solo contaminado por óleo diesel. Geotecnia (Lisboa), v. 110, p. 3-17, 2007.

Macdonald, R.W., Harner, T.T., Fyfe, J. (2005) Recent Climate Change in the Arctic and its Impact on Contaminant Pathways and Interpretation of Temporal Trend Data. Science ofthe Total Environment 342. DOI:10.1016/j.scitotenv.2004.12.059

Medeiros, P.M., Bícego, M.C., Castelao, R.M., Rosso, C.D., Fillmann, G., Zamboni, A.J. (2005) Natural and Anthropogenic Hydrocarbon Inputs to Sediments of Patos Lagoon Estuary, Brazil. Environment International 31.

DOI:10.1016/j.envint.2004.07.001

Moura, E. (2001) Estudo do Efeito de Aditivos Químicos e da Cal como Melhoradores de Adesividade em Misturas Asfálticas
Densas. Universidade de São Paulo. Dissertação de Mestrado. São Paulo, SP.

Oliveira, D.M., Castilhos Junior, A. B., Meiotello, E. (2003) Evaluation of the Solidification/Stabilization of Oily 'Borra' Using Caulinita and Vermiculite 'as' Adsorbents Materials. $22^{\circ}$ Congresso Brasileiro de Engenharia Sanitária e Ambiental. Joinville, SC.

Onofre, F.C., Lopes, M.M., Castelo Branco, V.T.F., Soares, J.B. (2009) Aplicação de Solo Contaminado por Petróleo em Misturas Asfálticas. 16a Reunião de Pavimentação Urbana. Belo Horizonte, MG.

Rojas, J.W.J., Consoli, N.C., Heineck, K.L. (2009) Tratamento de solo contaminado: análise do encapsulamento de metais pesados. Estudos Tecnológicos (Online), v. 5, p. 79-88, 2009. Porto Alegre, RS. DOI: 10.4013/ete.2009.51.06

Silva, R.M. da C. (2002) Utilização da Técnica de Fluorescência de Raios-X com Microssonda ( $\mu$-XRF) Aplicada à Amostra de Interesse Arqueológico. Tese de Doutorado; Universidade de São Paulo, SP.

Silva, S.A; Araújo, H. W. C; Oliveira, R. (1998) Reservatórios Profundos Tratando Esgoto Doméstico Bruto no Nordeste do Brasil: Ciclo do Enxofre. XXVII Congresso Interamericano de Engenharia Sanitária e Ambiental. Anais. Porto Alegre, ABES.

Standard methods for the examination of water and wastewater. Individual organic compounds- 20ª edição (CD), 1998.

Ubaldo, M.O., Motta, L.M.G., Fritzen, M.A.,Nascimento L.A.H. (2011) Utilização do Resíduo de Borra Oleosa em Pavimentação. Congressolbero-Latinoamericano do Asfalto. Rio de Janeiro, RJ.

Vane, C.H., Harrison, I., Kim, A.W. (2007) Polycyclic Aromatic Hydrocarbons (PAHs) and Polychlorinated Biphenyls (PCBs) in Sediments from the Mersey Estuary, U.K. The Science of the Total Environment 374. DOI:10.1016/j.scitotenv.2006.12.036

Venturini, N., Tommasi, L.R. (2004) Polycyclic Aromatic Hydrocarbons and Changes in the Trophic Structure of Polychaete Assemblages in Sediments of Todos os Santos Bay, Northeastern, Brazil. Marine Pollution Bulletin 48.

Wang, J.; Lewis, D.M.; Castranova, V.; Frazer, D.G.; Goldsmith, T.; Tomblyn, S.; Simpson, J.; Stone, D.; Afshari, A.; Siegel, P.D. (2001) Characterization of Asphalt Fume Composition under Simulated Road Paving Conditionsby GC/MS and Microflow LC/Quadrupole Time-of-Flight MS. Anal. Chem. 73:36913700.DOI: $10.1021 / \mathrm{ac} 010334 \mathrm{~m}$

WITT, G. (2002) Ocurrence and Transport of Polycyclic Aromatic Hydrocarbons in the Water Bodies of the Baltic Sea, Marine Chemistry, 79, 49-66. DOI:10.1016/S03044203(02)00035-X

Zheng, G.J., Richardson, B.J. (1999) Petroleum Hydrocarbons and Polycyclic Aromatic Hydrocarbons (PAHs) in Hong Kong Marine Sediments. Chemosphere 38. DOI:10.1016/S00456535(98)00470-6 